University of Nebraska - Lincoln

DigitalCommons@University of Nebraska - Lincoln

Faculty Publications: Department of Entomology

October 1997

\title{
Toxicity of Seven Monoterpenoids to Tracheal Mites (Acari: Tarsonemidae) and Their Honey Bee (Hymenoptera: Apidae) Hosts When Applied as Fumigants
}

\author{
Marion D. Ellis \\ University of Nebraska-Lincoln, mellis3@unl.edu \\ Frederick P. Baxendale \\ University of Nebraska-Lincoln, fbaxendale1@unl.edu
}

Follow this and additional works at: https://digitalcommons.unl.edu/entomologyfacpub

Part of the Entomology Commons

\footnotetext{
Ellis, Marion D. and Baxendale, Frederick P., "Toxicity of Seven Monoterpenoids to Tracheal Mites (Acari: Tarsonemidae) and Their Honey Bee (Hymenoptera: Apidae) Hosts When Applied as Fumigants" (1997). Faculty Publications: Department of Entomology. 147. https://digitalcommons.unl.edu/entomologyfacpub/147
}

This Article is brought to you for free and open access by the Entomology, Department of at DigitalCommons@University of Nebraska - Lincoln. It has been accepted for inclusion in Faculty Publications: Department of Entomology by an authorized administrator of DigitalCommons@University of Nebraska - Lincoln. 


\title{
Toxicity of Seven Monoterpenoids to Tracheal Mites (Acari: Tarsonemidae) and Their Honey Bee (Hymenoptera: Apidae) Hosts When Applied as Fumigants
}

\author{
MARION D. ELLIS AND FREDERICK P. BAXENDALE
}

Department of Entomology, University of Nebraska, 202 Plant Industries Building, Lincoln, NE 68583-0816

\begin{abstract}
J. Econ. Entomol. 90(5): 1087-1091 (1997)
ABSTRACT Laboratory bioassays were conducted to characterize the acute toxicity of 7 monoterpenoids to tracheal mites, Acarapis woodi (Rennie), and their honey bee, Apis mellifera L., hosts. Citral, thymol, carvacrol, $\alpha$-terpineol, pulegone, d-limonene, and menthol were applied as fumigants to mite-infested honey bees. Thymol and menthol were the most toxic compounds to honey bees, and $\alpha$-terpineol was the least toxic. Menthol, citral, thymol, and carvacrol were more toxic to tracheal mites than to honey bees. Pulegone, d-limonene, and $\alpha$-terpineol were more toxic to honey bees than to tracheal mites. Menthol was 18.9 times more toxic to tracheal mites than to honey bees at the $\mathrm{LC}_{50}$ concentrations; however, as the concentration increased, bee mortality increased more rapidly than mite mortality, and menthol was only 5.7 times more toxic at the $\mathrm{LC}_{90}$ concentrations. Probit regressions for bee and mite mortality were parallel for citral and thymol. Citral and thymol were 2.9 (2.5-3.3) and 2.0 (1.0-3.6) times more toxic to tracheal mites, respectively, at all concentrations estimated.
\end{abstract}

KEY WORDS Acarapis woodi, Apis mellifera, essential oils, monoterpenoids

MONOTERPENOIDS ARE THE principal components of essential oils and provide the essence of many higher plants including mint, pine, cedar, citrus, and eucalyptus (Templeton 1969). They are important allelochemicals in plant-arthropod interactions (Banthorpe and Charlwood 1980). Arthropods also synthesize monoterpenoids, and many function as semiochemicals in interactions between arthropods, as pheromones (Blum 1969), kairomones (Trouiller et al. 1991), and allomones (Ghent 1961).

Monoterpenoids can have both lethal and sublethal effects on mites (Acarina). Cook (1992) found that d-limonene, beta-pinene, alpha-pinene, and delta 3-carene were toxic to the spruce spider mite, Oligonychus ununguis (Jacobi). Furthermore, at concentrations below the calculated $\mathrm{LC}_{50} \mathrm{~s}$, all 4 compounds reduced oviposition, and 3 of the compounds increased movement. Lee et al. (1997) reported that most of the 30 monoterpenoids they tested for activity against the twospotted spider mite, Tetranychus urticae Koch, exhibited some degree of acaricidal activity, especially the alcohols, phenols, and ketones. Larson and Berry (1984) examined T. urticae fecundity and development on peppermint, Mentha piperita, leaves that differed in monoterpene content, but were unable to correlate monoterpene content of leaves with either fecundity or development. However, in tests conducted in unventilated petri dishes, the vapors from $5 \%$ solutions of menthol and pulegone reduced oviposition and increased mortality. Calderone et al.
(1991) examined 7 naturally occurring monoterpenoids in topical application and feeding tests for $A$. woodi control. They applied 1 dosage level of each compound to infested bees and reported acaricidal activity for $\alpha$-terpinene, terpineol, citronellal, and clove oil.

Citral, a monoterpenoid investigated in our study, serves as an alarm pheromone in several species of gregarious acarid mites (Kuwahara et al. 1980, Baker and Krantz 1984, Tuma et al. 1990). Baker and Krantz (1984) used citral as a control adjuvant in treating lily bulbs with dicofol (Kelthane) to control bulb mites, Rhizoglyphus robini Claparede. Citral is an alarm pheromone for this mite, and when used as an adjuvant, caused an increase in mite activity and contact with the acaricide. Citral also serves as a defensive chemical in some ant and bee species including the leafcutter ant, Atta sexdens L. (Blum et al. 1968).

Currently, the only acaricide registered for tracheal mite control in the United States is a monoterpenoid compound, menthol. Tracheal mite control with menthol was first demonstrated in Italy by Giavarini and Giordani (1966). Herbert et al. (1987), Moffett et al. (1987), Ellis and Simonds (1987), Cox et al. (1989), Moffett et al. (1989), Wilson et al. (1990), and Duff and Furgala (1991) have confirmed that menthol is effective against tracheal mite populations in the United States.

The target sites and modes of action have not been elucidated for the monoterpenoids, and only a few studies have examined this question (Lorber 
and Muller 1976, Andrews et al. 1980, Watanabe et al. 1990, and Ikawa et al. 1992). Lee et al. (1997) and Rice and Coats (1994) are currently investigating structure-activity relationships for monoterpenoids applied to various arthropods.

Although several monoterpenoids have shown toxicity to arthropods, most are not acutely toxic to mammals. Monoterpenoids are used widely as fragrance and flavoring ingredients (Croteau 1980) and in over-the-counter formulations of expectorants, decongestants, external analgesics, and antiseptics (Klocke 1987). Characteristics of these simple compounds that make them attractive for development as environmentally sound arthropod control agents include their selective arthropod toxicity, low mammalian toxicity, and biodegradability.

The objectives of this study were to characterize the acute fumigant toxicities of pulegone, carvacrol, $d$-limonene, citral, menthol, thymol, and $\alpha$ terpineol to honey bees and their tracheal mite parasites. These compounds represent a range of monoterpenoids and include 1 terpene hydrocarbon, 1 terpene aldehyde, 1 terpene ketone, and 4 terpene alcohols.

\section{Materials and Methods}

Technical grade samples of monoterpenoids were obtained from Aldrich (Milwaukee, WI). Vapor exposures were conducted in 1.9-liter glass jars. Monoterpenoids were weighed and dispensed into $3.7-\mathrm{ml}$ (1-dram) vials. The contents of the vials were dispersed on the inside surface of each jar; the vials and any remaining compound were then deposited in the jars. The jars were sealed and placed in a Precision Low Temperature Incubator (Model 816, GCA, Chicago, IL). All exposures were for a single 24 -h period at $35^{\circ} \mathrm{C}$ and a photoperiod of 12:12 (L:D) h. Humidity was not controlled. Preliminary studies were performed with each compound to determine the appropriate concentration ranges for testing. Six to 8 concentrations (micrograms of compound per milliliter volume of the jar) were selected and prepared for bioassay. A control group, which received no monoterpenoid, was included in each replication. Each treatment was repeated 3-6 times.

Honey bees infested with $A$. woodi were obtained from 9 colonies located on the University of Nebraska campus. All colonies were headed by Carniolan queens obtained from Wenner Apiaries (Glenn, CA). All colonies were treated with terramycin (Pfizer, New York, NY), fumidil-b (MidCon, Olathe, KS), and apistan (Zoecon, Dallas, TX) to control brood and adult bee diseases and parasites not of interest in this study. Adult worker bees were collected from the combs of the brood nest and caged in Benton mailing cages (Kelley, Clarkson, KY) supplied with queen cage candy (Laidlaw 1979). One cage of 10 worker bees was placed in each jar and constituted a replication. Cages were
Table 1. Honey bee responses to monoterpenoids fumigants

\begin{tabular}{lccc}
\hline \hline Monoterpenoid & $n$ & Slope \pm SEM & LC $_{50}(95 \% \mathrm{CL})$ \\
\hline Carvacrol & 470 & $5.53 \pm 0.42$ & $11.4(10.0-12.8)$ \\
Citral & 440 & $6.49 \pm 0.55$ & $10.1(8.9-11.4)$ \\
$d$-Limonene & 360 & $16.18 \pm 1.79$ & $10.4(9.9-10.9)$ \\
Menthol & 480 & $1.82 \pm 0.23$ & $5.3(3.3-7.1)$ \\
Pulegone & 360 & $6.73 \pm 0.67$ & $6.6(5.4-7.9)$ \\
Thymol & 400 & $1.81 \pm 0.22$ & $1.7(0.5-2.9)$ \\
$\alpha$-Terpineol & 420 & $13.77 \pm 1.61$ & $17.1(16.0-18.2)$ \\
\hline
\end{tabular}

$\mathrm{LC}_{50} \mathrm{~s}$ are expressed in micrograms of monoterpenoid per milliliter.

suspended in the middle of the jars by a wire tether. Bees were given water immediately before and after all bioassays and also received water twice daily after treatments until evaluations were completed. Bees from colonies with $30-80 \%$ mite prevalence were used in all bioassays. After treatment, bees were held in a dark storage area maintained at $21^{\circ} \mathrm{C}$. Relative humidity was not controlled during the holding period.

Bee mortality was based on no response to probing with minutin pins and was recorded at 24,48 , 72 , and $96 \mathrm{~h}$ after treatment. Mite mortality was measured 96-144 h after treatment. Live and dead mites were differentiated using methods described by Eischen et al. (1987). Prothoracic tracheae were removed laterally from the spiracle and medially at the bifurcations leading to the head and air sacs and were transferred to glass slides coated with glycerol. Tracheae were then teased open using minutin pins mounted in wooden probes. Adult and immature mites were scored as alive if they walked or moved within $15 \mathrm{~s}$ of observation. If no movement was observed, but they had the normal appearance of living mites (turgid and grey to pearl colored), they also were scored as alive. Mites were scored as dead if they were discolored with colors ranging from yellow to dark brown or if they had appendages appressed to their bodies and were desiccated in appearance. In this study, eggs were scored as alive if turgid and as dead if flat or shriveled.

Data were analyzed using POLO (LeOra Software 1991), for probit analyses and SAS (SAS Institute 1985) for analyses of variance. The arcsine transformation was applied to all percentage mortality data for life stage effects that were analyzed by analysis of variance. Monoterpenoids were selected based on a review of the literature and recommendations by Joel Coats (Iowa State University) who is currently investigating this class of compounds.

\section{Results}

Honey Bee Bioassays. All probit regression estimates for bee mortality were significant (Table 1). Compounds were significantly different ( $\alpha=0.05$ ) in toxicity at any lethal concentration value if their 95\% CL did not overlap. Thymol was the most toxic compound. Surprisingly, menthol, the monoterpe- 
Table 2. Adult tracheal mite responses to monoterpenoids fumigants

\begin{tabular}{lccc}
\hline Monoterpenoid & $n$ & Slope + SEM & LC $_{50}(95 \% \mathrm{CL})$ \\
\hline Carvacrol & 551 & $1.76 \pm 0.35$ & $7.8^{a}$ \\
Citral & 130 & $7.76 \pm 0.57$ & $3.6(3.3-3.8)$ \\
Menthol & 999 & $1.04 \pm 0.17$ & $0.3(0.01-0.8)$ \\
Thymol & 581 & $2.00 \pm 0.29$ & $0.9(0.3-1.3)$ \\
\hline
\end{tabular}

$\mathrm{LC}_{50} \mathrm{~s}$ are expressed in micrograms of monoterpenoid per milliliter.

${ }^{a}$ Not significant.

noid currently registered for tracheal mite control, was more toxic to honey bees than were most of the other compounds examined in this study. Slopes of the probit regression estimates were not equal for all compounds; therefore, relative toxicities could only be compared at specific lethal concentration values.

Mite Bioassays. Citral and menthol were more toxic to adult tracheal mites than to honey bees (Table 2). Although thymol was numerically more toxic to mites, the difference was not significant ( $\alpha$ $=0.05$ ). Carvacrol was significantly more toxic to mites than bees; however, although the regression was significant, the fit was not good enough to estimate $95 \% \mathrm{CL}$. Pulegone, $d$-limonene, and $\alpha$ terpineol were more toxic to host honey bees than to tracheal mites, and probit regression estimates could not be generated for these compounds.

Menthol was the most toxic compound to tracheal mites. The slopes for menthol, thymol, and citral (the 3 most effective compounds) were not parallel $(\alpha=0.05)$; therefore, relative toxicities could only be compared at specific lethal concentration values. Lethal concentration values with nonoverlapping $95 \% \mathrm{CL}$ (Table 2) were considered significantly different $(\alpha=0.05)$. There were no significant differences in natural mortalities among untreated control groups $(P=0.270)$.

Relative Toxicities to Bees and Mites. Figs. 1 and 2 show combined plots of the probit regression

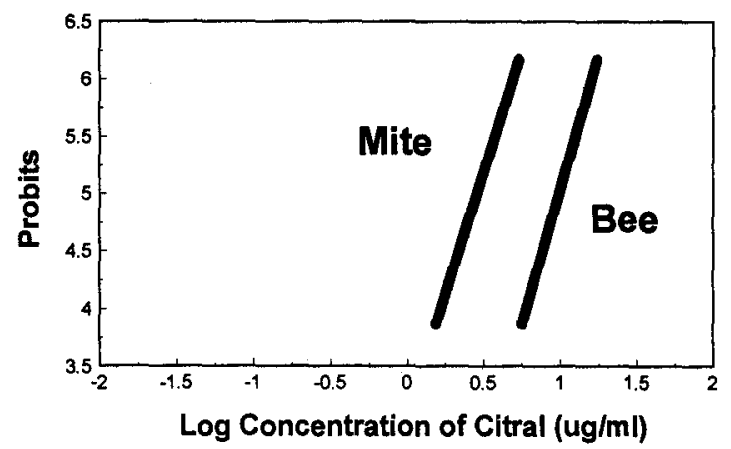

Fig. 1. Bee and mite mortality responses to citral when applied as a fumigant to mite-infested honey bees. Bee mortality slope $=6.49(5.94-7.04)$, intercept $=-6.54$ $(-5.96$ to -7.12$)$. Mite mortality slope $=7.76(7.19-8.33)$, intercept $=-4.28(-3.95$ to -4.61$)$.

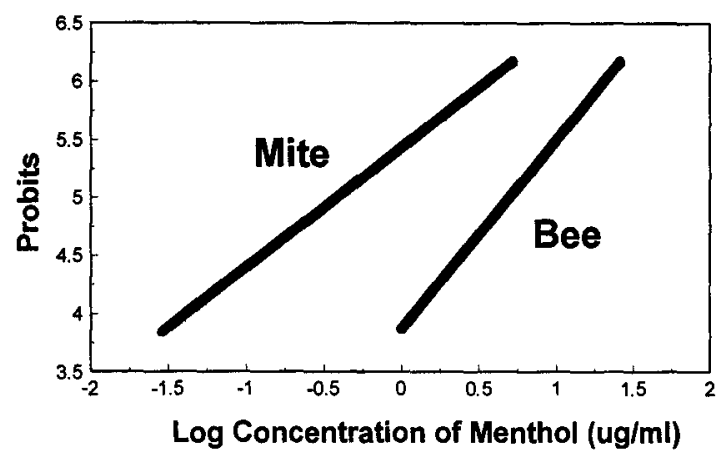

Fig. 2. Bee and mite mortality responses to menthol when applied as a fumigant to mite-infested honey bees. Bee mortality slope $=1.82(1.58-2.06)$, intercept $=-1.31$ $(-1.07$ to -1.55$)$. Mite mortality slope $=1.04(0.87-1.21)$, intercept $=0.58(0.47-0.69)$.

estimates for bee and adult mite responses to citral and menthol, respectively. Regression estimates were parallel for citral. Citral was 2.9 times more toxic to mites at all concentrations. The regressions were not parallel for menthol. Menthol was 52.0, 18.8 , and 5.7 times more toxic to mites at the $\mathrm{LC}_{10}$, $\mathrm{LC}_{50}$, and $\mathrm{LC}_{90}$, respectively. Thymol and carvacrol were numerically more toxic to mites, although the differences were not significant statistically $(\alpha=$ 0.05 ).

Relative Toxicities to Life Stages of A. woodi. Citral was the only compound that gave significant control $(P<0.05)$ of all tracheal mite life stages at a concentration close to the $\mathrm{LC}_{50}$ for their honey bee hosts (Table 3). Thymol gave significant con-

Table 3. Relative toxicities of monoterpenoids fumigants to 3 life stage of tracheal mites

\begin{tabular}{|c|c|c|c|c|c|}
\hline Compound & $n$ & Dose & $\begin{array}{c}\text { Life } \\
\text { stage }\end{array}$ & $\begin{array}{l}\% \text { mortality } \\
\pm \text { SEM }\end{array}$ & $p^{a}$ value \\
\hline \multirow[t]{3}{*}{ Carvacrol } & 514 & 10 & Adults & $0.625 \pm 0.085$ & $0.010^{*}$ \\
\hline & & & Larvae & $0.239 \pm 0.081$ & 0.312 \\
\hline & & & Eggs & $0.156 \pm 0.103$ & 0.355 \\
\hline \multirow[t]{3}{*}{ Citral } & 688 & 10 & Adults & $1.00 \pm 0.031$ & $0.0001^{*}$ \\
\hline & & & Larvae & $0.972 \pm 0.079$ & $0.0001^{*}$ \\
\hline & & & Eggs & $0.967 \pm 0.084$ & $0.0001^{*}$ \\
\hline \multirow[t]{3}{*}{$d$-Limonene } & 719 & 10 & Adults & $0.114 \pm 0.036$ & 0.492 \\
\hline & & & Larvae & $0.077 \pm 0.073$ & 0.653 \\
\hline & & & Eggs & $0.000 \pm 0.053$ & - \\
\hline \multirow[t]{3}{*}{ Menthol } & 976 & 5 & Adults & $0.937 \pm 0.032$ & $0.0001^{*}$ \\
\hline & & & Larvae & $0.356 \pm 0.102$ & 0.191 \\
\hline & & & Eggs & $0.225 \pm 0.097$ & 0.378 \\
\hline \multirow[t]{3}{*}{ Pulegone } & 671 & 7 & Adults & $0.192 \pm 0.125$ & 0.902 \\
\hline & & & Larvae & $0.147 \pm 0.117$ & 0.937 \\
\hline & & & Eggs & $0.046 \pm 0.028$ & 0.289 \\
\hline \multirow[t]{3}{*}{$\alpha$-Terpineol } & 677 & 15 & Adults & $0.363 \pm 0.067$ & 0.051 \\
\hline & & & Larvae & $0.159 \pm 0.074$ & 0.402 \\
\hline & & & Eggs & $0.000 \pm 0.077$ & - \\
\hline \multirow[t]{3}{*}{ Thymol } & 486 & 3 & Adults & $0.854 \pm 0.048$ & $0.0001^{*}$ \\
\hline & & & Larvae & $0.647 \pm 0.078$ & $0.018^{*}$ \\
\hline & & & Eggs & $0.274 \pm 0.086$ & 0.074 \\
\hline
\end{tabular}

Concentrations are expressed in micrograms of monoterpenoid per milliliter. ${ }^{*}, P \leq 0.05$ represent tests in which mite mortality was significantly greater than natural mortality.

${ }^{a}$ Probability that mortality was greater than natural mortality. 
trol of adults and larvae. Menthol and carvacrol gave significant control of adults only (Table 3 ).

\section{Discussion}

Honey bee mortality responses to thymol and menthol extended over a wider range of concentrations than did responses to the other 5 compounds bioassayed. With the other 5 compounds, once the response threshold concentration was reached, small increases in concentration increased bee mortality. All monoterpenoid $\mathrm{LC}_{50}$ values fell in a narrow range $(1.7-17.1 \mu \mathrm{g} / \mathrm{ml})$. Rice and Coats (1994) found $\mathrm{LC}_{50} \mathrm{~s}$ in the same range for menthol, pulegone, and citral when applied to Musca domestica L. In their study, menthol, pulegone, and citral had $\mathrm{LC}_{50}$ s of $3.6,9.2$, and $13 \mu \mathrm{g} / \mathrm{ml}$, respectively. Interestingly, although thymol was the most toxic compound to honey bees examined in this study $\left(\mathrm{LC}_{50}\right.$ of $\left.1.7 \mu \mathrm{g} / \mathrm{ml}\right)$, thymol was not highly toxic to $M$. domestica in Rice and Coats' study ( $\mathrm{LC}_{50}$ of 142 $\mu \mathrm{g} / \mathrm{ml}$ ). Some compounds assayed in this study were more toxic to honey bees than to their $A$. woodi parasites, although others were more toxic to A. woodi. Results obtained in this study support Rice and Coats' (1994) observations that monoterpenoid potencies vary considerably, and that minor structural differences can elicit major differences in toxicity.

Citral, which has not been reported previously to be toxic to tracheal mites, killed all life stages of tracheal mites at concentrations below those required to kill their honey bee hosts. The margin of safety was 2.9 , and this relationship was constant for all concentrations. Citral was the only compound tested that exhibited both uniform margins of safety at all concentrations and no overlap in the confidence limits for bee and mite mortality at any concentration. The performance of citral in our bioassays makes it a candidate for development as a control agent for $A$. woodi. Citral is an alarm pheromone for some species of gregarious acarid mites (Kuwahara et al. 1980) and its effect on A. woodi behavior merits investigation. Citral may be useful as an adjuvant at low concentrations if found to affect the behavior of $A$. woodi making them more vulnerable to acaricides.

Menthol was the most toxic compound to $A$. woodi in our studies. It also had the largest margin of safety (18.9) at the $\mathbf{L C}_{50}$; however, the margin of safety declined to 5.7 at the $\mathrm{LC}_{90}$. The low toxicity of menthol to mite eggs and larvae and relatively high toxicity to honey bees are undesirable attributes. Menthol is currently registered as a fumigant for use in honey bee colonies. Beekeepers purchased 5.7 metric tons of menthol in 1993 (Mann Lake Supply, Hackensack, MN) to control tracheal mites.

Thymol controlled A. woodi adults and larvae, but it also was the most toxic compound to bees in this study. The margin of safety (2.0) was not large and the $95 \% \mathrm{CL}$ for bee and mite toxicity over- lapped at the $\mathrm{LC}_{10}$ and $\mathrm{LC}_{50}$ concentrations. It may be difficult to use thymol at brood nest temperatures without inducing unacceptable levels of bee mortality. Chiesa (1991) was able to control V. jacobsoni in honey bee colonies with thymol without noticeable damage to the colonies at temperatures ranging from 5 to $9^{\circ} \mathrm{C}$. However, Gal et al. (1992) found thymol applications deleterious to bees when temperatures reached $27-28^{\circ} \mathrm{C}$. Overlap in the $\mathrm{LC}_{50}$ confidence limits for bee and mite mortality found in this study supports the findings of Gal and his colleagues that thymol is too toxic to bees for use at high temperatures. Further studies of concentration-temperature interactions are needed to determine optimum conditions for thymol application. If the relative toxicities to bees and mites change at cooler temperatures, a satisfactory treatment window may be found.

Although carvacrol did not provide a good fit to the probit regression model, it has acaricidal properties and should be examined in future studies. Gal et al. (1992) obtained 81-92\% control of V. jacobsoni under what they described as "subtropical" conditions with origanum oil (carvacrol); however, they also reported a high degree of robbing in treated colonies. Pulegone, $d$-limonene, and $\alpha$-terpineol were more toxic to honey bees than to tracheal mites and should be eliminated as candidate compounds for A. woodi control.

The dose-response relationships reported in this study provide a foundation for future investigations of monoterpenoid fumigant use to control $A$. woodi in honey bee colonies. Length of exposure, temperature, and humidity are factors that can influence the activity of monoterpenoid fumigants and merit further investigation. Likewise, mode of action studies can provide insight into how best to use monoterpenoids. The potential use of these selective and fully biodegradable compounds in the management of parasitic bee mites is encouraging.

\section{References Cited}

Andrews, R. E., L. W. Park, and K. D. Spence. 1980. Some effects of Douglas fir terpenes on certain microorganisms. Appl. Environ. Microbiol. 40: 301-304.

Baker, G. T., and G. W. Krantz. 1984, Alarm pheromone production in the bulb mite, Rhizoglyphus robini Claparede, and its possible use as a control adjuvant in lily bulbs, pp. 686-692. In D. A. Griffiths and C. E. Bowman [eds.], Acarology VI. Horwood, New York.

Banthorpe, D. V., and B. V. Charlwood. 1979. Secondary plant products, pp. 185-220. In E. A. Bell and B. V. Charlwood [eds.], Encyclopedia of plant physiology. Springer, New York.

Blum, M. S. 1969. larm pheromones. Annu. Rev. Entomol. 14: 57-80.

Blum, M. S., F. Padovani, and E. Amante. 1968. Alkanones and terpenes in the mandibular glands of Atta species. Comp. Biochem. Physiol. 26: 291-299.

Calderone, N. W., W. A. Bruce, G. Allen-Wardell, and H. Shiminuki. 1991. Evaluation of botanical compounds for control of the honey bee tracheal mite, Acarapis woodi. Am. Bee J. 131: 589-591. 
Chiesa, F, 1991. Effective control of varroatosis using powdered thymol. Apidologie 22: 135-145.

Cook, S. P. 1992. Influence of monoterpene vapors on spruce spider mite, Oligonychus ununguis, adult females. J. Chem. Ecol. 18: 1497-1504.

Cox, R. L., J. O. Moffett, W. T. Wilson, and M. Ellis. 1989. Effects of late spring and summer menthol treatment on colony strength, honey production, and tracheal mite infestation levels. Am. Bee J. 129: 547549.

Croteau, R. 1980. The biosynthesis of terpene compounds, pp. 13-33. In R. Croteau [ed.], Fragrance and flavor substances. Haarman \& Reimer, Pattensen, West Germany.

Duff, S. R., and B. Furgala. 1991. Some effects of menthol on honey bee tracheal mite infestations in nonmigratory honey bee colonies in Minnesota. Am. Bee J. 131: 315-317.

Eischen, F. A., J. S. Pettis, and A. Dietz. 1987. A rapid method of evaluating compounds for the control of Acarapis woodi (Rennie). Am. Bee J. 127: 99-101.

Ellis, M. D., and C. Simonds. 1987. Menthol fumigation of caged honey bees to prevent the spread of tracheal mites in package and queen bee shipments. Proc. Am. Bee Res. Conf. Am. Bee J. 127: 844.

Gal, H., Y. Slabezki, and Y. Lensky. 1992. A preliminary report on the effect of origanum oil and thymol applications in honey bee (Apis mellifera $\mathrm{L}$.) colonies in a subtropical climate on population levels of Varroa jacobsoni. BeeScience 2: 175-179.

Ghent, R. L. 1961. Adaptive refinements in the chemical defense mechanisms of certain Formicinae. Ph.D. dissertation, Cornell University, Ithaca, NY.

Giavarini, I., and G. Giordani. 1966. Study of acarine disease of honey bee. Final technical report E15. Instituto di Apicultora, Bologna, Italy.

Herbert, E. W., Jr., H. Shiminuki, J. C. Matthenius, Jr. 1987. The effects of two candidate compounds on Acarapis woodi in New Jersey. Am. Bee J. 127: 776778

Ikawa, M., S. P. Mosley, and L. J. Barbero. 1992. Inhibitory effects of terpene alcohols and aldehydes on growth of green alga, Chlorella pyrenoidosa. J. Chem. Ecol. 18: 1755-1759.

Klocke, J. A., M. V. Darlington, and M. F. Balandrin. 1987. 1,8-Cineole (eucalyptol), a mosquito feeding and ovipositional repellent from volatile oil of Hemizonia fitchii (Asteraceae). J. Chem. Ecol, 13: 21312141.

Kuwahara, Y., H. Fukami, S. Ishii, K. Matsumoto, and Y. Wada. 1980. Pheromone study on acarid mites III. Citral: isolation and identification from four species of acarid mites, and its possible role. Jpn. J. Sanit. Zool. 31: $49-52$.

Laidlaw, Jr., H. H. 1979. Contemporary queen rearing. Dadant and Sons, Hamilton, IL.
Larson, K. C., and R. E. Berry. 1984. Influence of peppermint phenolics and monoterpenes on twospotted spider mite (Acari: Tetranychidae). Environ. Entomol. 13: 282-285.

Lee, S., R. Tsao, C. Peterson, and J. R. Coats. 1997. Insecticidal activity of monoterpenoids to the western corn rootworm (Coleoptera: Chrysomelidae), twospotted spider mite (Acari: Tetranychidae), and house fly (Diptera: Muscidae). J. Econ. Entomol. (in press).

LeOra Software. 1991. POLO-PC a user's guide to Probit Or LOgit analysis. LeOra Software, Berkley, CA.

Lorber, P., and W. H. Muller, 1976. Volatile growth inhibitors produced by Salvia leucophylla: Effects on seedling root tip ultrastructure. Am. J. Bot. 63: 196200.

Moffett, J. O., R. I. Cox, M. Ellis, and R. Rivera. 1987. Effect of winter treatments with menthol on populations of tracheal mites, Acarapis woodi, on honey bees in Tamaulipas, Mexico and Nebraska. Am. Bee J. 127: $848-849$.

Moffett, J. O., R. L. Cox, M. Ellis, R. Rivera, W. T. Wilson, and D. Cardoso-T. 1989. Menthol reduces winter populations of tracheal mites, Acarapis woodi, in honey bees from Mexico and Nebraska. Southwest. Entomol. 14: 57-65.

Rice, P. J., and J. R. Coats. 1994. Insecticidal properties of several monoterpenoids to the house fly (Diptera: Muscidae), red flour beetle (Coleoptera: Tenebrionidae), and Southern corn rootworm (Coleoptera: Chrysomelidae). J. Econ. Entomol. 87: 1172-1179.

SAS Institute. 1985. SAS/STAT user's guide, version 6 ed. SAS Institute, Cary, NC.

Templeton, W. 1969. An Introduction to the chemistry of terpenoids and steroids. Butterworths, London.

Trouiller, J., G. Arnold, Y. LeConte, and C. Masson. 1991. Temporal pheromonal and kairomonal secretion in the brood of honey bees. Naturwissenschaften 78: $368-370$.

Tuma, D., R. N. Sinha, W. E. Muir, and D. Abramson. 1990. Odor volatiles associated with mite-infested bin-stored wheat. J. Chem. Ecol. 16: 713-724.

Watanabe, K., K. Umeda, Y. Kurita, C. Takayama, and M. Miyakado. 1990. Two insecticidal monoterpenes, telfairine and aplysiaterpenoid $\mathrm{A}$, from the red alga, Plocamium telfairiae: structure elucidation, biological activity, and molecular topographical consideration by a semiempirical molecular orbital study. Pest. Biochem. Physiol. 37: 275-286.

Wilson, W. T., R. L. Cox, J. O. Moffett, and M. Ellis. 1990. Improved survival of honey bee (Apis mellifera L.) colonies from long-term suppression of tracheal mites (Acarapis woodi Rennie) with menthol. Bee Sci. 1: $48-54$.

Received for publication 25 October 1996; accepted 19 May 1997. 